\title{
ANALISIS PERBANDINGAN MENGGUNAKAN DATA SEKUNDER PERBAIKAN TANAH DENGAN LIMESTONE DAN PASIR BATU PADA LEMPUNG LUNAK
}

\author{
Prayoga $^{1}$, dan Gregorius Sandjaja $S^{2}$ \\ ${ }^{1}$ Program Studi Sarjana Teknik Sipil, Universitas Tarumanagara, Jl. Letjen S. Parman No.1 Jakarta \\ prayoga.325160047@stu.untar.ac.id \\ ${ }^{2}$ Program Studi Sarjana Teknik Sipil, Universitas Tarumanagara, Jl. Letjen S. Parman No.1 Jakarta \\ gregoriuss@ft.untar.ac.id
}

\begin{abstract}
The work on a building requires a strong foundation, which is able to accept all the loads that will be given. The strength of the foundation is positioned at the base, the ground above the building being built. In the construction of major highways such as toll roads, the load applied to the soil is the building load, the vibration load and the weight of passing vehicles. This can damage the road building if it is not supported by a strong foundation. Strong soils are that are dense, low plasticity, and have little settlement. However, the soils in Tangerang are clay soils that do not meet the criteria for land that can be used. Soil improvement or soil reinforcement is needed to ensure the soil is strong and able to accept all the loads that will be given. Various kinds of soil improvements can be applied in the Kunciran-Cengkareng toll road project, but the most cost-effective is the sandstone and limestone mixture soil improvement. Using the literature obtained, it will be compared which land improvement has the highest effectiveness for cases such as the construction on the Kunciran-Cengkareng Toll Road which has been completed and has started operations.
\end{abstract}

Keywords: Soil Stabilization, Limestone Mixture, Sandstone.

\begin{abstract}
ABSTRAK
Pengerjaan sebuah bangunan membutuhkan dasar pondasi yang kuat, yang mampu menerima semua beban yang akan diberi. Kekuatan pondasi tersebut berposisi sebagian besar pada dasar, yaitu pada tanah di atas bangunan dibangun. Pada pengerjaan jalan raya utama seperti tol, beban yang diberi terhadap tanah merupakan beban bangunan begitu pula beban getaran dan berat kendaraan yang melewati. Hal tersebut dapat merusak bangunan jalan jika tidak didukung oleh pondasi yang kuat. Tanah yang kuat merupakan tanah yang padat, memiliki plastisitas yang rendah, dan penurunan yang kecil. Namun, tanah-tanah di Tangerang merupakan tanah lempung yang belum cukup memenuhi kriteria tanah yang dapat digunakan secara langsung. Perbaikan tanah atau perkuatan tanah dibutuhkan untuk memastikan tanah yang akan dipakai kuat dan sanggup menerima segala beban yang akan diberi. Berbagai macam perbaikan tanah dapat diaplikasikan di proyek tol Kunciran-Cengkareng, tetapi perbaikan tanah yang paling efektif dan tidak memakan banyak biaya adalah perbaikan tanah pasir batu dan campuran batu kapur. Menggunakan litelatur yang didapat, akan dibandingkan perbaikan tanah yang mana, yang memiliki efektivitas tertinggi untuk kasus seperti pembangunan pada Tol Kunciran-Cengkareng yang sudah selesai pengerjaan dan sudah mulai beroperasi.
\end{abstract}

Kata Kunci: Stabilisasi Tanah, Campuran Batu Kapur, Pasir Batu

\section{PENDAHULUAN}

Negara Indonesia adalah negara kepulauan terbesar yang berisi dengan banyak daerah tanah lunak. Jenis tanah tersebut merupakan jenis tanah yang memiliki kuat geser, koefisien permeabilitas, kompresibilitas, dan daya dukung tahan yang rendah. Hal ini memberi tantangan bagi konstruktor bangunan dikarenakan oleh diperlukannya perbaikan tanah (soil stabilization). Sejak tahun 1990, beragam metode perbaikan tanah lunak dipakai dalam mengatasi permasalahan tanah lunak di Indonesia, salah satunya yaitu Limestone dan Pasir Batu (Warsiti, 2009).

Jalan Tol Cengkareng-Batu Ceper-Kunciran adalah sebuah jalan tol yang membentang dari Cengkareng hingga Kunciran di Jabodetabek, Indonesia. Jalan tol ini merupakan bagian dari jaringan Jakarta Outer Ring Road 2 
yang akan menghubungkan Bandara Internasional Soekarno-Hatta ke Cilincing. Jalan tol tersebut akan terkoneksi dengan Tol Jakarta-Tangerang, Tol Kunciran-Serpong, serta Prof. Dr. Ir. Jalan Tol Soedijatmo (Wiyana, Setyarini, \& Prahatinigsih, 2018)

Studi analisis perlu dilakukan untuk meyakinkan bahwa tanah sudah cukup kuat untuk menampung segala beban dari sebuah struktur merupakan hal penting yang tidak boleh dianggap remeh. Kekuatan tanah di setiap tempat berbeda-beda, begitu pula dengan sifat dan karakteristik tanah (Ariyani, 2009). Pada proyek ini, dapat dilihat dan disimpulkan dari data sekunder yang diteliti oleh Wiyana (2018), data tanah berdominan lempung lunak, maka diperlukanya perbaikan tanah pada lapangan sebelum melanjutkan pekerjaan proyek.

Tujuan dari penyusunan penelitian ini adalah untuk mengkaji bagaimana perbandingan hasil dari perbaikan tanah yang menggunakan pasir batu dengan tanah yang menggunakan campuran batu kapur. Perbaikan tanah pasir batu dan campuran batu kapur memiliki keunggulan dan kekurangan masing-masing, penelitian ini dimaksud untuk mengetahui material campuran yang tepat untuk perbaikan tanah dengan kondisi tertentu. Begitu pula dengan menggali lebih dalam karakteristik masing-masing perbaikan tanah, spesifikasi apa saja yang terpengaruh dengan adanya perbaikan tanah tersebut.

Penelitian dilakukan dengan data yang dapat diperoleh dengan bantuan dosen pembimbing dan dosen yang disaat pembuatan laporan ini, sedang bekerja kontrak dengan proyek yang dijadikan studi kasus. Tanah yang dibandingkan berasal dari pondasi tanah pada proyek pembangunan jalan Tol Cengkareng-Batu Ceper-Kunciran STA $26+221-$ STA 38 + 937 (mainroad) dan STA 1 + 850 - STA 4 + 350 (ramp 1, ramp 4). Pembangunan diatas tanah lempung lunak (clay) dan data tanah merupakan data sekunder. Pada perbaikan tanah dasar menggunakan Limestone dan Sirtu. (Wiyana, Setyarini, \& Prahatinigsih, 2018)

Data umum dari proyek Jalan Tol Cengkareng-Kunciran adalah sebagai berikut:
1. Nama Proyek : Jalan Tol Cengkareng-Kunciran
2. Lokasi Proyek : Tangerang
3. Pengelola : PT MKC
4. Panjang Jalan : :15,2 Km

Penelitian ini dimulai dengan dilakukannya studi literature dengan batasan topik-topik yang relevan dengan isi studi skripsi ini. Lalu dilanjutkan dengan pengambilan dan pengolahan data terhadap studi kasus yang akan dipelajari, selanjutnya data akan diolah dan dikaji berdasarkan rumusan masalah.

\section{DATA PROYEK}

\section{Analisis sesuai literatur yang didapat.}

Perbandingan akan dilakukan dengan data asumsi pada proyek tol Cengkareng-Kunciran. Menggunakan hasil data penelitian dari literature yang memiliki data dasar yang paling mendekati data asumsi pada proyek, dapat dikaji seperti pada Tabel 1.

Tabel 1. Data pada lapisan paling atas pada proyek jalan tol

\begin{tabular}{|c|c|c|c|c|c|c|c|}
\hline No. Area & Area 1 & Area 2 & Area 3 & Area 4 & Area 5 & Area 6 & Area 7 \\
\hline 1 & 2 & 3 & 4 & 5 & 6 & 7 & 8 \\
\hline Jarak & $\begin{array}{l}\text { STA } 26 \\
\text { BL-14 s/d } \\
\text { STA } 29 \\
\text { BL-20 (3 } \\
\mathrm{km})\end{array}$ & $\begin{array}{l}\text { STA } 31 \\
\text { BL-25 \& } \\
\text { STA } 31 \\
\text { BL-25A } \\
(200 \mathrm{~m})\end{array}$ & $\begin{array}{l}\text { STA } 31 \\
\text { BL-26 s/d } \\
\text { STA BL- } \\
\text { 27A (1 } \\
\mathrm{km})\end{array}$ & $\begin{array}{l}\text { STA } \\
\text { BL-30 }\end{array}$ & $\begin{array}{l}\text { STA 33 } \\
\text { BL-30B } \\
\text { s/d STA } \\
33 \text { BL- } \\
31(100 \mathrm{~m})\end{array}$ & $\begin{array}{l}\text { STA } 33 \\
\text { BL-32 s/d } \\
\text { STA 33 } \\
\text { BL-33A } \\
(200 \mathrm{~m})\end{array}$ & $\begin{array}{l}\text { STA } 34 \text { BL-36 } \\
\text { s/d STA } 34 \\
\text { BL-36A (50 } \\
\text { m) }\end{array}$ \\
\hline $\begin{array}{l}\text { Jenis Tanah, } \\
\text { Kedalaman 0- } \\
4 \mathrm{~m}\end{array}$ & Soft Clay & $\begin{array}{l}\text { Soft to } \\
\text { Medium } \\
\text { Clay }\end{array}$ & Soft Clay & $\begin{array}{l}\text { Soft } \\
\text { Clay }\end{array}$ & Soft Clay & Soft Clay & $\begin{array}{l}\text { Soft to Medium } \\
\text { Clay }\end{array}$ \\
\hline $\begin{array}{l}\text { N-SPT } \\
\text { munculkan 0- } \\
4\end{array}$ & $0-8$ & $0-14$ & $0-7$ & $0-7$ & $0-5$ & $0-4$ & $0 .-14$ \\
\hline
\end{tabular}

Sumber: (Wiyana, Setyarini, \& Prahatinigsih, 2018)

Berdasarkan data tanah yang tersedia, data tanah yang tidak diperoleh pada data sekunder, akan diasumsikan sesuai dengan studi literature yang diteliti. Studi yang diteliti adalah studi penambahan batu kapur pada tanah ekspansif di Bojonegoro dan studi penambahan pasir batu pada tanah lempung lunak di Lampung. 
Pengambilan data, hasil dan kesimpulan didapat dari litelatur yang diedarkan secara online. Penelitian dilakukan pada tanah lempung ekspansif yang berada di Bojonegoro., yang dapat dilihat data tanahnya pada Tabel 2.

Tabel 2. Data tanah asli Ngasem, Bojonegoro

\begin{tabular}{lcr}
\hline \multicolumn{1}{c}{ Jenis Percobaan } & Satuan & \multicolumn{1}{c}{ Nilai } \\
\hline \multicolumn{1}{c}{ Spesific Gravity (Gs) } & 2 & \multicolumn{1}{c}{3} \\
\hline Lolos Saringan no.200 & $\%$ & 2,685 \\
\hline Liquid Limit & $\%$ & 97,03 \\
\hline Plastic Limit & $\%$ & 31,5 \\
\hline Shrinkage Limit & $\%$ & 35,59 \\
\hline Plasticity Indeks & $\%$ & 4,77 \\
\hline Fraksi Lempung & $\%$ & 44 \\
\hline Berat Isi Kering & gr/cc & 0,8186 \\
\hline KAO & $\%$ & 21,9 \\
\hline CBR Soaked & $\%$ & 4,66 \\
\hline CBR Unsoaked & $\%$ & 14,76 \\
\hline Swelling & $\%$ & 5,5088 \\
\hline Sudut Geser & $\circ$ & 20,61 \\
\hline Kohesi & $\mathrm{kg} / \mathrm{cm} 2$ & 0,842 \\
\hline
\end{tabular}

Sumber: (Ranggaesa, Zaika, \& Suroso, 2017)

Dari penelitian yang diuji oleh Ranggaesa (2017), tanah yang dicampur oleh campuran batu kapur, nilai indeks plastisitas dan batas penyusutan mengalami kenaikan di setiap penambahan campuran batu kapur. Tanah yang diteliti pada studi tersebut merupakan tanah bersifat ekspansif, dengan adanya penambahan batu kapur, resiko pengembangan pada tanah tersebut mengalami penurunan yang cukup tinggi.

Sedangkan studi literatur yang menyangkut penambahan pasir batu pada tanah lempung adalah studi literatur yang diteliti oleh Ramadhani (2015). Pengujian dilakukan pada 3 sampel tanah yang diambil dari 3 desa yang berbeda di Lampung yang dapat dilihat pada Tabel 3.

Tabel 3. Data tanah asli dari 3 desa di Lampung*

\begin{tabular}{|c|c|c|c|c|c|}
\hline \multirow{2}{*}{ No. } & \multirow{2}{*}{$\begin{array}{c}\text { Pengujian } \\
\quad(1\end{array}$} & \multicolumn{3}{|c|}{ Hasil Uji } & \multirow{2}{*}{ Satuan } \\
\hline & & Tanah 1 & Tanah 2 & Tanah 3 & \\
\hline 1 & 2 & 3 & 4 & 5 & 6 \\
\hline 1 & Kadar Air & 27,25 & 35,54 & 50,15 & $\%$ \\
\hline 2 & Berat Jenis & 2,33 & 2,65 & 2,53 & $\mathrm{Gr} / \mathrm{cm} 3$ \\
\hline 3 & Berat Volume & 1,38 & 1,37 & 0,96 & $\mathrm{Gr} / \mathrm{cm} 3$ \\
\hline 4 & Lolos Saringan No. 200 & 69,21 & 85,05 & 90,17 & $\%$ \\
\hline 5 & Liquid Limit & 33,09 & 65,16 & 67,88 & $\%$ \\
\hline 6 & Plastic Limit & 19,97 & 34,51 & 36,69 & $\%$ \\
\hline 7 & Plasticity Index & 13,12 & 30,66 & 32,012 & $\%$ \\
\hline 8 & Kadar Air Optimum & 17 & 23 & 30 & $\%$ \\
\hline 9 & Berat isi kering optimum & 1,36 & 1,59 & 1,65 & $\mathrm{Gr} / \mathrm{cm} 3$ \\
\hline
\end{tabular}

Sumber: (Ramadhani, Iswan, \& Jafri, 2015)

Penelitian yang dilakukan oleh Taufik, Iswan, dan Jafri, menghasilkan data bukti bahwa penambahan pasir dapat memengaruhi kekuatan uji triaxial dan menurunkan nilai indeks plastisitas.

Maka dari kedua studi dan jenis tanah pada lapangan yang dikutip pada penelitian Wiyana (2018), data lain diasumsikan agar dapat dikorelasikan perkiraan perubahaan jenis dan kekuatan tanah pada lapangan seperti pada Tabel 4. 
Tabel 4. Data Asumsi yang diambil dari kedekatan sifat dan jenis tanah.

\begin{tabular}{lcr}
\hline \multicolumn{1}{c}{ Jenis Percobaan } & Satuan & \multicolumn{1}{c}{ Nilai } \\
\hline Liquid Limit & 2 & 3 \\
\hline Plastic Limit & $\%$ & 80 \\
\hline Shrinkage Limit & $\%$ & 34 \\
\hline Plasticity Indeks & $\%$ & 6,5 \\
\hline Kadar Air Optimum & $\%$ & 50 \\
\hline CBR Soaked & $\%$ & 22 \\
\hline CBR Unsoaked & $\%$ & 4,5 \\
\hline Swelling & $\%$ & 15 \\
\hline Sudut Geser & $\%$ & 6 \\
\hline Kohesi & $\circ$ & 20,5 \\
\hline
\end{tabular}

\section{HASIL STUDI BERDASARKAN ASUMSI}

\section{Menggunakan campuran batu kapur}

Menggunakan hasil penelitian pada literature, maka perkiraan perubahan yang terjadi adalah tanah pada lapangan proyek, seandainya dicampur dengan 6\%, 8\%, 9\%, dan 10\% campuran batu kapur maka kemungkinan batas-batas Atterberg yang akan diperoleh seperti tercantum pada Tabel 2.

Pada batas-batas Atterberg, kemungkinan batasan yang akan terjadi jika dilakukan penambahan campuran batu kapur pada tanah di lapangan adalah adalah pada Tabel 5 dan Gambar 1.

Tabel 5. Perubahan pada batas-batas Atterberg.

\begin{tabular}{lcccc}
\hline \multicolumn{1}{c}{ Jenis Sampel } & LL (\%) & PL (\%) & SL (\%) & PI (\%) \\
\hline \multicolumn{1}{c}{1} & 2 & 3 & 4 & 5 \\
\hline Tanpa Campuran & 80 & 43,6 & 17,3 & 17,4 \\
Campur 6\% kapur & 57 & 44,2 & 17,9 & 13,3 \\
Campur 8\% kapur & 53,5 & 44,6 & 18,5 & 12,4 \\
Campur 9\% kapur & 53 & 45,1 & 19 & 10,4 \\
Campur 10\% kapur & 51,5 & 43,6 & 17,3 & 17,4 \\
\hline
\end{tabular}

Sumber: (Ranggaesa, Zaika, \& Suroso, 2017)

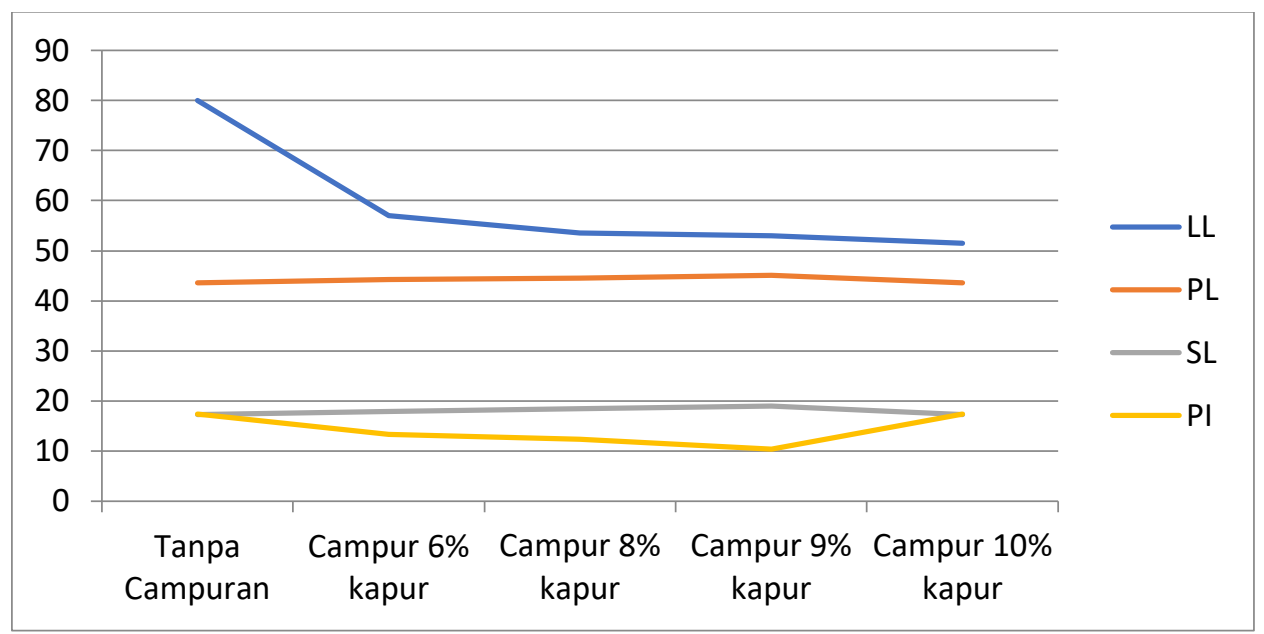

Gambar 1. Grafik perbandingan campuran kapur dengan nilai batas Atterberg

Kemungkinan perubahan pada nilai kadar air optimum yang akan terjadi jika dilakukan penambahan campuran batu kapur pada tanah di lapangan adalah seperti yang ditampilkan pada Tabel 6 dan Gambar 2. 
Tabel 6. Perubahan pada kadar air optimum

\begin{tabular}{lc}
\hline \multicolumn{1}{c}{ Jenis Sampel } & W (\%) \\
1 & 2 \\
Tanpa Campuran & 22 \\
Campur 6\% kapur & 19,5 \\
Campur 8\% kapur & 19,9 \\
Campur 9\% kapur & 20,8 \\
Campur 10\% kapur & 22,1 \\
\hline
\end{tabular}

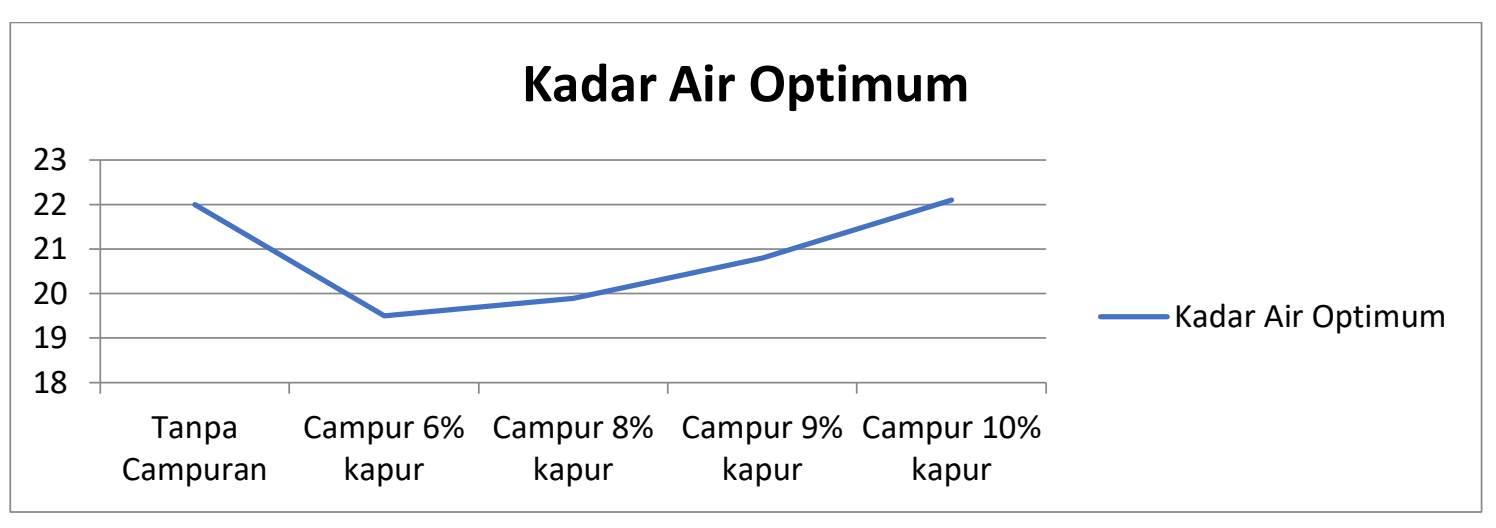

Gambar 2. Grafik perbandingan campuran kapur dengan nilai kadar air optimum

Dari tabel diatas, hasil uji kadar air pada setiap campuran dengan persentase yang berbeda-beda, kadar air mengalami penurunan di setiap penambahan campuran kapur. Namun, pada penambahan campuran kapur sebanyak 9\%, kadar air bertambah dikarenakan campuran tidak mengikat dengan baik jika kapur berlebih ditambahkan.

Pengaruh kenaikan maupun penurunan kekuatan pada tanah dapat diperkirakan seperti yang dapat dilihat pada Tabel 7. Perubahan setiap penambahan juga dapat dilihat pada Gambar 3.

Tabel 7. Perubahan pada nilai CBR

\begin{tabular}{lcc}
\hline \multirow{2}{*}{ Jenis Sampel } & \multicolumn{2}{c}{ Nilai CBR (\%) } \\
\cline { 2 - 3 } 1 & Soaked & Unsoaked \\
Tanpa Campuran & 2 & 3 \\
Campur 6\% kapur & 4,5 & 15 \\
Campur 8\% kapur & 11,1 & 21,99 \\
Campur 9\% kapur & 11,88 & 22,76 \\
Campur 10\% kapur & 10,71 & 20,43 \\
\hline
\end{tabular}




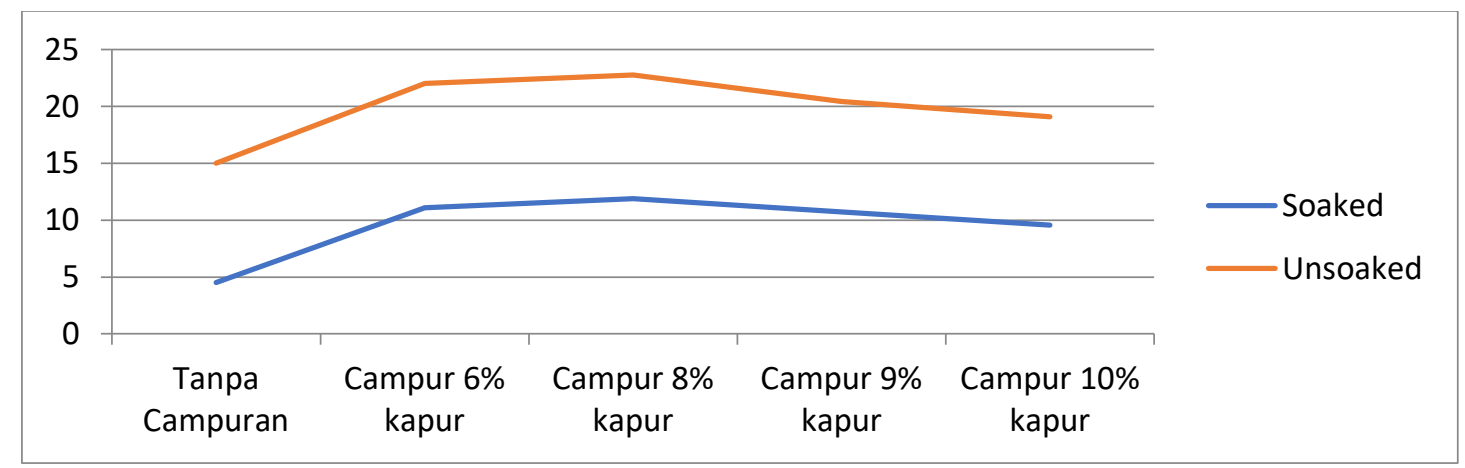

Gambar 3. Grafik perbandingan campuran kapur dengan nilai CBR unsoaked dan soaked

Penambahan campuran kapur dapat menambah kekuatan tanah campuran seperti yang dapat dilihat di tabel diatas. Pada penambahan 6 dan 8 persen, campuran bertambah nilai CBR, namun pada penambahan 9\% keatas, nilai CBR mulai terjadi penurunan, dikarenakan campuran yang tidak baik jika terlalu banyak terdapat material kapur pada campuran.

Kemungkinan perubahan pada nilai swelling yang akan terjadi jika dilakukan penambahan campuran batu kapur pada tanah di lapangan dapat dilihat pada Tabel 8. Perubahan setiap penambahan dapat dilihat pada Gambar 4.

Tabel 8. Perubahan pada nilai Swelling

\begin{tabular}{lcc}
\hline \multicolumn{1}{c}{ Jenis Sampel } & Swelling (\%) & Penurunan Nilai Swelling (\%) \\
\hline 1 & 2 & 3 \\
\hline Tanpa Campuran & 6 & 0 \\
Campur 6\% kapur & 0,22 & 96,47 \\
Campur 8\% kapur & 0,15 & 97,5 \\
Campur 9\% kapur & 0,14 & 98,1 \\
Campur 10\% kapur & 0,09 & 98,54 \\
\hline
\end{tabular}

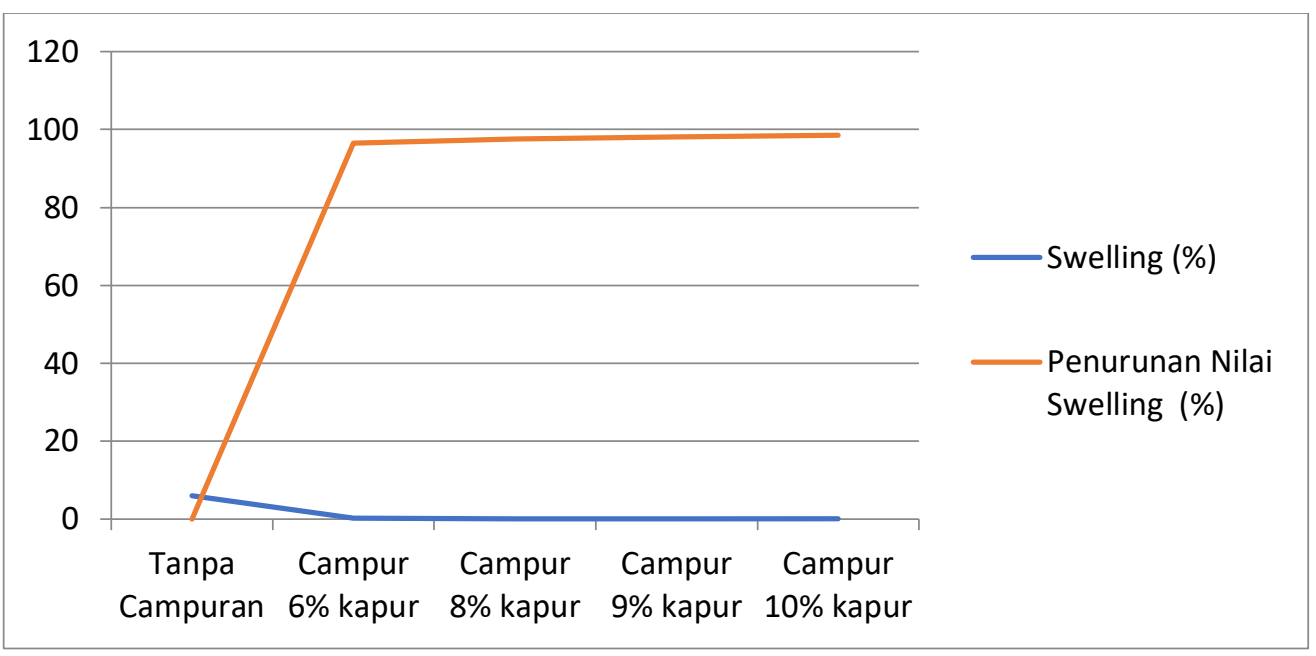

Gambar 4. Grafik perbandingan campuran kapur dengan nilai swelling

Material kapur yang bercampur dengan butiran mineral lempung dapat menghasilkan kalsium silikat yaitu gel yang cukup keras untuk dapat mengikat partikel tanah (Ariyani, 2009). Gel silika mengikat serta melekat pada partikelpartikel tanah dan menutupi pori pada tanah. Dengan proses terjadinya hal tersebut, terjadi penurunan nilai indeks plastisitas dan nilai pada batas cair. Begitu pula semakin rendah nilai plastisitas maka dapat disampaikan bahwa semakin rendah potensi mengembang (Soetjiono, 2008). Dapat disimpulkan bahwa, penambahan campuran material kapur dapat meningkatkan kualitas dan kekuatan dari tanah asli serta dapat memperkecil kemungkinan terjadinya pengembangan. 


\section{Menggunakan Campuran Pasir Batu}

Menggunakan hasil penelitian pada literature, sampel tanah yang peling mendekati dengan data asumsi tanah pada lapangan proyek adalah sampel tanah 3 yang diambil dari Desa Blimbing Sari, Kecamatan Jabung, Lampung Timur. Perkiraan perubahan yang terjadi adalah tanah pada lapangan proyek, dicampur dengan 0\%, 5\%, 10\%, dan 15\% campuran pasir batu.

Kemungkinan perubahan pada kadar air optimum yang terjadi jika tanah pada lapangan dicampur dengan pasir batu pada beberapa persentase, dapat dilihat pada Tabel 9 dan perkembangan setiap penambahan pada Gambar 5.

Tabel 9. Perubahan pada kadar air optimal

Ket : KAO = Kadar Air Optimum

\begin{tabular}{cc}
\hline Tanah + Pasir & KAO $\left(\omega_{\text {opt }}\right)$ \\
\hline 1 & 2 \\
\hline Campuran $0 \%$ & $22 \%$ \\
Campuran $5 \%$ & $20 \%$ \\
Campuran $10 \%$ & $19 \%$ \\
Campuran $15 \%$ & $18 \%$ \\
\hline
\end{tabular}

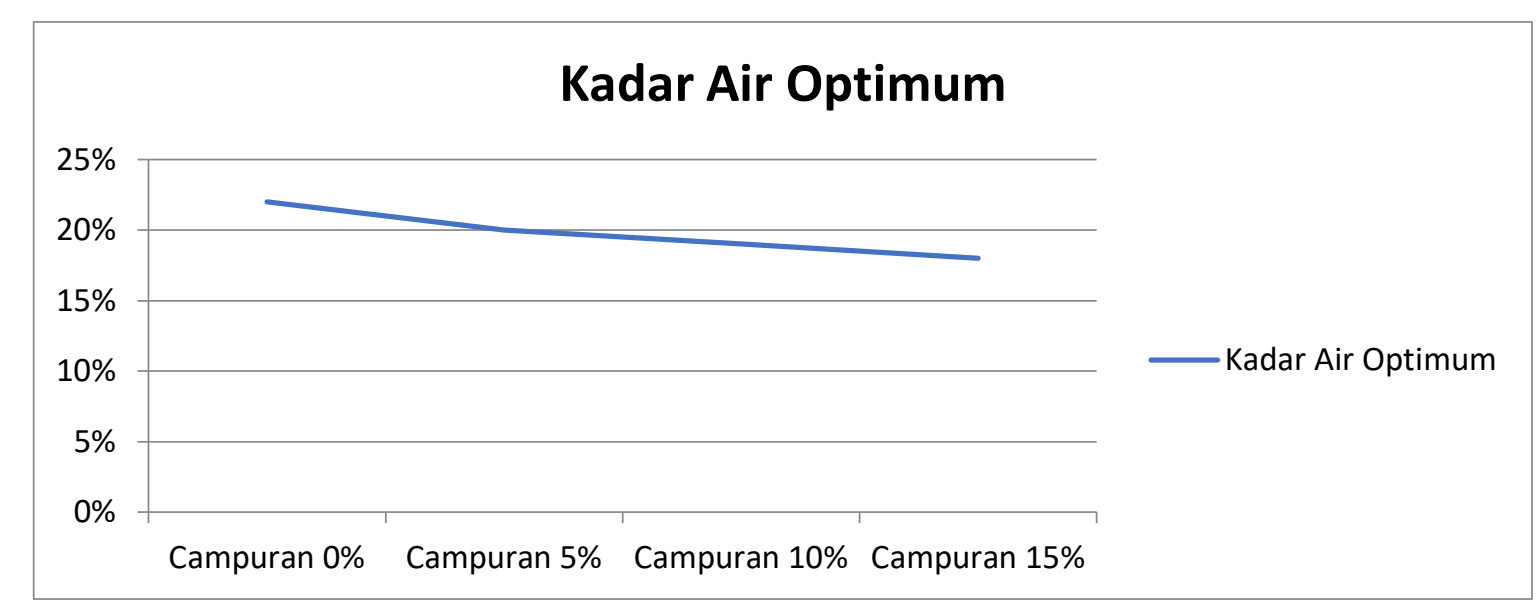

Gambar 5. Grafik antara campuran pasir batu terhadap nilai kadar air optimum

Seperti yang dilihat pada tabel, perubahan yang terjadi adalah pengurangan kadar air optimum sebesar 2\% setiap pemberian 5\% pasir. Hal ini terjadi karena makin banyak campuran pasir akan mengakibatkan rongga pada tanah terisi oleh pasir sedangkan air tidak berpengaruh pada pasir. Jadi kebutuhan air pada tanah untuk mencapai kemampatan tergantikan oleh campuran pasir sehingga menimbulkan penurunan kadar air.

Pada penambahan tanah dengan campuran pasir batu, perkiraan yang akan terjadi pada nilai-nilai Atterberg dapat dilihat pada Tabel 10 dan perbandingan nya pada Gambar 6.

Tabel 10. Perubahan pada batas-batas Atterberg

\begin{tabular}{cccc}
\hline Tanah + Pasir & LL & PL & PI \\
\hline 1 & 2 & 3 & 4 \\
\hline Campuran 0\% & $80 \%$ & $34 \%$ & $50 \%$ \\
Campuran 5\% & $78,01 \%$ & $37,48 \%$ & $44,52 \%$ \\
Campuran 10\% & $76,50 \%$ & $42,64 \%$ & $37,86 \%$ \\
Campuran 15\% & $74,70 \%$ & $46,58 \%$ & $32,12 \%$ \\
\hline
\end{tabular}




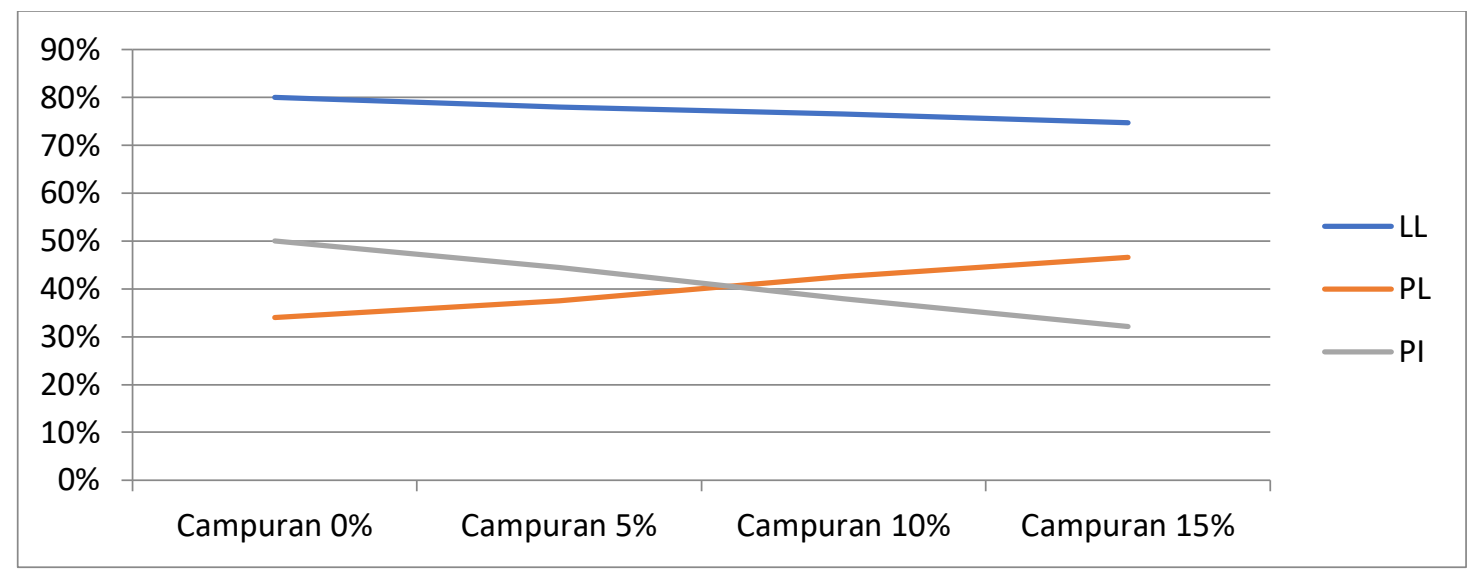

Gambar 6. Grafik antara campuran pasir batu terhadap nilai batas-batas Atterberg

Hal ini disebabkan pasir dapat membuat kadar air yang dibutuhkan tanah tersebut menjadi lebih banyak untuk merubah tanah dari keadaan semi padat menjadi keadaan plastis. Semakin besar penambahan kadar pasir maka nilai batas plastispun akan semakin membesar. Sedangkan pada nilai batas cair dan plastisitas indeksanya mengalami penurunan yang disebabkan karena sifat pasir mengisi rongga - rongga pada tanah sehingga membuat ikatan tanah menjadi sedikit renggang, tidak mengikat air, dan dapat dengan mudah meloloskan air. Sehingga pasir dapat digunakan sebagai pengendali sifat plastis tanah tersebut.

Pada penambahan tanah dengan campuran pasir batu, perkiraan yang akan terjadi pada nilai geser langsung dapat dilihat pada Tabel 11 dan perubahannya pada Gambar 7.

Tabel 11. Perubahan pada geser langsung

\begin{tabular}{ccc}
\hline Tanah + Pasir & Sudut Geser Dalam $(\Phi)$ & Kohesi \\
\hline 1 & 2 & 3 \\
\hline Campuran $0 \%$ & $20,5^{\circ}$ & $0,842 \mathrm{~kg} / \mathrm{cm} 2$ \\
Campuran $5 \%$ & $25,18^{\circ}$ & $0,842 \mathrm{~kg} / \mathrm{cm} 2$ \\
Campuran $10 \%$ & $27,38^{\circ}$ & $0,842 \mathrm{~kg} / \mathrm{cm} 2$ \\
Campuran $15 \%$ & $29,61^{\circ}$ & $0,842 \mathrm{~kg} / \mathrm{cm} 2$ \\
\hline
\end{tabular}

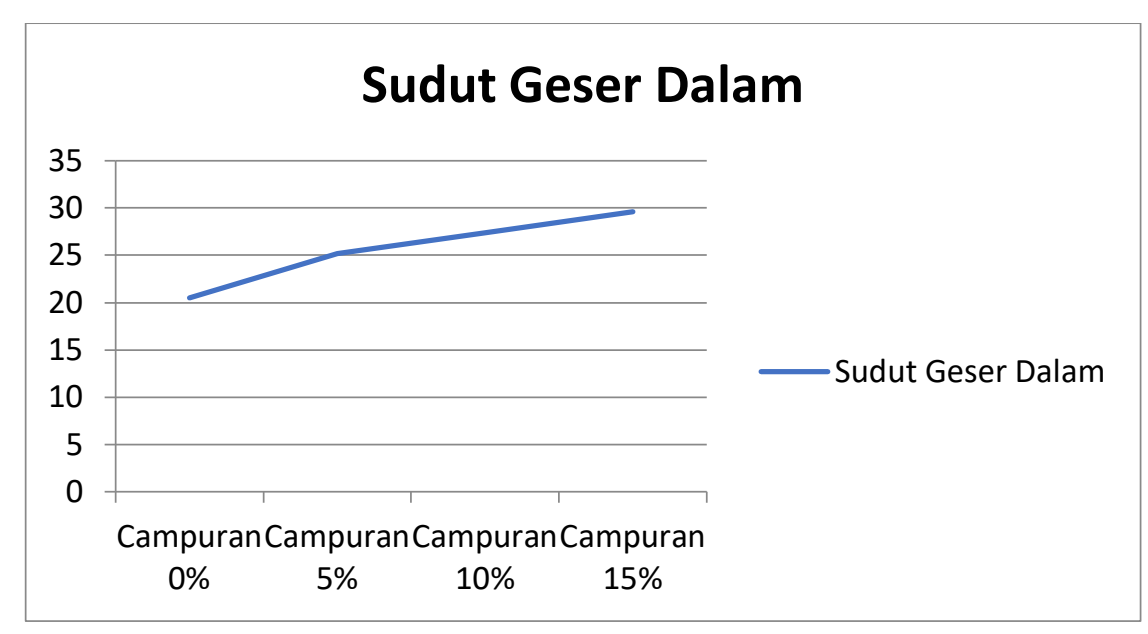

Gambar 7. Grafik antara campuran pasir batu terhadap nilai sudut geser dalam

Dilihat dari tabel hasil perubahan yang terjadi, nilai kohesi semakin mengecil nilainya meskipun tidak terlalu signifikan hal ini dikarenakan sifat pasir yang non kohesif dan mudah meloloskan air. Sedangkan nilai sudut geser dalam tanah mengalami peningkatan yang tidak konstan nilainya. 


\section{Perbaikan Tanah Pada Proyek}

Perbaikan Tanah yang dilakukan di Proyek Tol ini adalah Perbaikan Tanah Batu Kapur. Berdasarkan perhitungan analisis pada nilai-nilai data tanah yang mungkin terjadi pada daya dukung dan sifat tanah sesuai dengan literatur yang diteliti, kekuatan pada tanah lapangan meningkat dan optimal pada penambahan campuran batu kapur 8\% dengan tanah asli lapangan. Dengan pertimbangan dari perameter dan daya dukung tanah, perbaikan tanah menggunakan campuran batu kapur sudah cukup memberi kekuatan yang dibutuhkan untuk menampung beban jalan tol. Pada kedalaman 0-4 meter dapat ditinjau bahwa tanah membutuhkan perbaikan sebelum dapat dipakai sebagai alas dan fondasi pengerjaan proyek.

\section{KESIMPULAN DAN SARAN}

\section{Kesimpulan}

Dari analisis perbandingan dengan literature pada skripsi ini, tidak dapat diambil kesimpulan perbaikan tanah mana yang paling bagus, dikarenakan pada kasus penelitian skripsi ini, ketiga studi kasus memiliki hasil data uji lab yang berbeda-beda. Pada masa pandemic Covid-19, kesulitan mendapatkan data yang diperlukan untuk mengambil kesimpulan, maka hanya didapat perbandingan penambahan kekuatan pada batas-batas tertentu. Nilai batas cair dan indeks plastisitas mengalami penurunan seiring dengan bertambahnya kadar kapur, sedangkan nilai batas plastis dan nilai batas susut mengalami kenaikan seiring dengan bertambahnya kadar kapur. Kenaikan nilai CBR soaked dan unsoaked tertinggi terjadi pada penambahan persentase kapur 8\% dan semakin banyak kadar kapur yang ditambahkan maka semakin kecil swelling yang terjadi.

\section{SARAN}

Perlu dilakukan studi lebih mendalam jika batu kapur dapat memberikan efek yang lebih positif terhadap perbaikan tanah karena ketika air bercampur dengan batu kapur, maka akan memperkuat ikatan pada butir tanah.

\section{DAFTAR PUSTAKA}

Ariyani, N. (2009). Pengaruh Penambahan Kapur Pada Tanah Lempung Ekspansif Dari Dusun Bodrorejo Klaten. Yogyakarta: Teknik Sipil Fakultas Teknik UKRIM.

Ramadhani, T., Iswan, \& Jafri, M. (2015). Hubungan Batas Cair dan Plastisitas Indeks Tanah Lempung yang. JRSDD Edisi Juni 2015, 3(2), 291-302.

Ranggaesa, R. A., Zaika, Y., \& Suroso. (2017). Pengaruh Penambahan Kapur Terhadap Kekuatan dan Pengembangan (Swelling) Pada Tanah Lempung Ekspansif Bojonegoro. Jurnal Universitas Brawijaya, 7.

Soetjiono, C. (2008). Perbaikan Tanah Untuk Penerapan Teknologi Konstruksi di Atas Tanah Lunak. JSDA, 4(2), 161.

Warsiti. (2009). Meningkatkan CBR dan Memperkecil Swelling Tanah Sub Grade dengan Metode Stabilisasi Tanah dan Kapur (Vol. 14). Semarang: Peliteknik Negeri.

Wiyana, S. E., Setyarini, J. A., \& Prahatinigsih, A. (2018). Kajian Dua Kelompok Data Tanah Dari Hasil Uji Bor Dalam Pada Proyek Jalan Tol. Jurnal Mitra Teknik Sipil, 205-213. 
Analisis Perbandingan Menggunakan Data Sekunder

Prayoga, et al.

Perbaikan Tanah dengan Limestone dan Pasir Batu pada

Lempung Lunak 